\title{
Physician-patient communication in the prevention of female reproductive tract infections: some limitations
}

\author{
Comunicação entre médicos e mulheres na \\ prevenção das infecções do trato reprodutivo: \\ algumas limitações
}

María Y. Makuch 1 Neury José Botega 2 Luis Bahamondes 3

\footnotetext{
1 Centro de Pesquisa das Doenças Materno-Infantil de Campinas, Universidade Estadual de Campinas. C. P. 6181, Campinas, SP 13081-970, Brasil.

2 Departamento de Psicologia Médica e Psiquiatria, Universidade Estadual de Campinas. C. P. 1170, Campinas, SP 13081-970, Brasil.

3 Departamento de Obstetrícia e Ginecologia, Universidade Estadual de Campinas.

C. P. 6181, Campinas, SP 13081-970, Brasil. bahamond@uring.unicamp.br
}

\begin{abstract}
The objective of this study was to describe the information that women with tubal infertility recalled having received from physicians when they consulted for a reproductive tract infection (RTI) and the information physicians reported having provided to women consulting for RTIs. Interviews were conducted with 16 women presenting primary tubal infertility selected on the basis of purposeful sampling criteria. Also, 15 physicians working in the public health network in the city of Campinas, Brazil, were selected at random and interviewed. Analysis of the women's statements concerning previous RTI-related medical consultations showed that they did not recall having received any information on ei ther prevention or the impact of RTI on their reproductive future. Analysis of interviews with physicians showed that the information they provided to women consulting for RTIs was incomplete and unclear. The information women re called having received and that which physicians remembered having provided at the time of treating a patient with RTI was similar. In conclusion, these women lacked adequate or complete information and that it was probably not possible for them to adopt measures to avoid repetition of RTI and minimizerisk of tubal infertility.

Key words ReproductiveTract Infection; Female's Infertility; Infertility; Preventive Medicine
\end{abstract}

Resumo O objetivo deste estudo foi descrever a informação que mulheres com esterilidade tubária lembravam haver recebi do dos médi cos quando elas compareceram à consulta em virtude de infeções do trato reprodutivo (ITR), assi m como a informação que os médi cos referi ram dar-Ihes no momento da consulta. Foram entrevistadas 16 mul heres com esterilidade primária de causa tubária, selecionadas seguindo o critério de amostra proposital. Foram sel ecionados ao acaso e entrevistados 15 médi cos da rede pública de Campinas, SP, Brasil. A análi se das respostas das mulheres mostrou que el as não lembravam de ter recebi do informação a respei to de mei os de prevenção ou sobre o impacto das ITRs em seu futuro reprodutivo. A análise das entrevistas com os médi cos revel ou que a informação que el es declararam prover às mul heres em questão sobre as formas de transmi ssão, os riscos para o futuro reprodutivo e meios de prevenção foi incompl eta ou pouco clara. A informação que as consulentes lembravam haver recebi do e a que os médicos referiram dar sobre as ITR foi similar. Em conclusão, essas mulheres não receberam informação adequada ou completa, e provavel mente não foi possível que implementassem meios de prevenção para evitar a repeti ção de ITR e minimizar o risco de esterilidade tubária.

Palavras-chave Infecções do Trato Reprodutivo; Infertilidade Feminina; Infertilidade; Medicina Preventiva 


\section{Introduction}

Primary infertility due to tubal obstruction is common in developing countries as a consequence of the high prevalence of reproductive tract infections (RTIs) (Rowe \& Vikhlyaeva, 1988). In these countries, RTI is a common disease in women that is frequently neglected by the public health sector due to the erroneous concept that such infections are not fatal, and that diagnosis and treatment are expensive. Another common belief among health providers is that RTIs only affect a small proportion of sexually active women, such as commercial sex workers and/or women with multiple partners. Consequently, preventive information, when offered, is focused on the so-called risk groups (Dixon-Mueller \& Wasserheit, 1991).

Primary tubal infertility due to RTI is a common diagnosis at the Infertility Clinic of the Universidade Estadual de Campinas, São Paulo, Brazil. A study conducted at this clinic found that $37 \%$ of women who consulted for infertility between 1978 and 1982 presented tubal obstruction, and another study in 1996 showed that $42 \%$ presented this diagnosis (Fernandes \& Bahamondes, 1996).

This type of infertility requires complex diagnostic and treatment procedures, and the possibility of obtaining a pregnancy is limited, even with in vitro fertilization. According to the American Society for Reproductive Medicine, between 15 and $20 \%$ of couples who attempt this procedure succeed in achieving a pregnancy (Society for Assisted Reproductive Technology, 1998).

Primary tubal infertility due to RTI is preventable. Considering that $11 \%$ of women develop tubal obstruction after one RTI , $23 \%$ after two infections, and 54\% after three infections, many of the women with tubal infertility have probably had more than one infection, and it is possible that they have consulted more than once at health services (Hinting et al., 1993). When an RTI is identified, treatment must be initiated immediately, along with counseling on sexual transmission of the infection, risk of acquiring another infection, risk to future reproductive life, and notification of the partner (Hinting et al., 1993). Thus, information, education, and counseling are essential to the promotion of reproductive health and particularly important for the reproductive future of women with RTI (UN, 1994).

The objective of this study was to describe the information that women with primary tubal infertility recalled having received from physicians when they consulted for an RTI and that which physicians reported having provided to women consulting for RTIs.

\section{Subjects and methods}

This was a qualitative study conducted between November 1995 and September 1996 at Infertility Clinic of the Department of Obstetrics and Gynecology, Universidade Estadual de Campinas (UNICAMP), Brazil. In-depth interviews were conducted with 16 women presenting primary tubal infertility. To ensure that tubal obstruction was a consequence of RTI, only women with primary infertility diagnosed by laparoscopy were included, those with endometriosis and/ or a history of abdominal or pelvic surgery were excluded. In this study RTI was used to refer to the syndromes of vaginitis, cervicitis, and pelvic inflammatory disease (PID) (Elias, 1991).

Women were selected following a purposeful sampling criteria (Patton, 1991). The sample size was established through saturation of information (Denzin \& Lincoln, 1994).

Interview guidelines were developed to assure that all relevant themes would be discussed. Information was gathered on: history of vulvar itching, vaginal discharge, vaginitis, pelvic pain, PID, treatments, and the information women had received when presenting these symptoms in the past. Interviews also focused on whether they knew or suspected that such previous events bore any relationship to their present tubal infertility. All interviews were conducted by a senior psychologist and were audiotaped and transcribed.

Fifteen physicians were selected at random among those working in the city's public health network. Doctors were asked about the number of women they had examined during the month prior to the interview and about the most frequent diagnosis they had made during this period. They were also asked about medical practices, attitudes, and information they provided to women consulting for RTIs.

The study was approved by the Scientific and Ethics Review Committee of the institution. All participants were volunteers and signed an informed consent form. Interviews were conducted in private.

\section{Data analysis}

The tapes were transcribed verbatim and reviewed to identify categories for analysis ( $\mathrm{Mi}$ nayo, 1993). In the interviews with women, the main categories were related to what they re- 
called about past episodes that permitted the identification of reproductive tract infections, treatments, and the information they recalled having received on preventive measures. In the interviews with physicians, the categories identified referred to the most frequent diagnosis, treatment for RTI, and information provided about the transmission and preventive measures against RTIs.

\section{Results}

Interviews with women

Mean age of the women was 27 years (range 1935). Mean time of infertility was 5.5 years (range 1-12 years). Only one of the women interviewed was a university student, four women had attended school for up to 4 years, and 11 had attended from 5 to 8 years of school.

All the participating women reported a history of symptoms including vulvar itching, vaginitis, cervicitis, and/ or vaginal discharge, and they stated having received treatment for these complaints. When asked directly if they recalled having a history of RTI in the past, ten women expressed never having had one, six women recalled having had an RTI, and three said that it was recurrent. Data provided on these symptoms were analyzed by two physicians trained in Gynecology, who concluded that the 16 women in the study had a history of RTI. There was no divergence in their conclusions.

The women provided detailed reports of their symptoms, treatment, and relief. However, when asked about the information they received from physicians about the etiology of these complaints, most had difficulty answering. Some women did not recall having received any information, while others stated that the information provided had been unclear or confusing. For these women, the sexual transmission of RTIs was not clear. They reported that sexuality was discussed casually or in dubious terms (if at all). Most of the women did not recall having received any information on either the risk posed by RTIs for their future fertility or on measures to prevent RTIs. Only one woman commented that a physician had informed her that she would have "problems getting pregnant in the future, because she had a tubal infection". For the other 15 women, the diagnosis of tubal infertility was a surprise.

\section{Interviews with physicians}

Ten of the fifteen physicians interviewed were male. Mean age was 33 years (range 27-47). At the time of the interview, time on the job in the public health service ranged from one month to 17 years. Physicians reported that patients' most frequent complaints during gynecological consultations were vaginal discharge, pelvic pain, and menstrual disorders. When asked if they had treated women with RTI in the month prior to the interview, all except one answered in the affirmative. The mean number of consultations they reported was 25, ranging from 2 to 90.

When asked about women's most frequent concerns when consulting for RTIs, the physicians referred to relief of symptoms. Most of the physicians reported that women were worried about whether the infection was transmitted through sexual intercourse, whether they could continue to work and take care of their children, and whether their condition was related to cervical cancer and/ or HIV infection. Doctors reported that only a few women were worried about the relationship between RTI and their future reproductive health.

When asked about their recommendations to women consulting for RTIs, all reported medical treatment for women and occasionally for the partners and most advised women to use condoms or abstain from sex during treatment of RTI. Some physicians said they preferred to recommend sexual abstinence rather than condom use because many men refuse to use condoms. They provided information only to women, because men did not come to consultations.

Most physicians reported not discussing the sexual transmission of RTIs with the women. Some reported that providing information on the sexual transmission of RTIs creates a "social problem", because women want to know if their husbands have other partners. Only two of the physicians interviewed reported counseling regarding the risk of RTI for future infertility.

\section{Discussion}

Based on the selection criteria and information provided by the interviews, it is possible to infer that all the women participating in the study had a history of RTI and that three had recurrent infections. The information these women remembered having received on RTI prevention was vague and unclear, and they 
were unable to establish a relationship between the prior RTI and present tubal infertility. This was probably the reason for surprise in 15 of the 16 women when receiving the diagnosis of tubal obstruction. They did not establish links between the episodes for which they had sought treatment in the past, the RTI they probably had at that time, and the present tubal infertility.

Analysis of interviews with physicians showed that apparently they had no problems talking to women about diagnosis and treatment, but that they did experience difficulty discussing the sexual transmission of most RTIs with women. If sexuality is not openly discussed, it is difficult for women to understand the risks of these infections and to take preventive measures.

When women's and physicians' interviews were compared, the information women recalled having received and that which physicians reported having provided to women consulting for RTIs was similar. We could speculate that because this discussion implies sociocultural and personal values, communication about sexual issues was weak. As a result, the etiology of some RTIs has become a taboo about which little or nothing is said (Roter et al., 1990).

Prevention of RTIs includes recommendation of mutual monogamy, sexual abstinence, or condom use. Some physicians reported that they preferred the indication of sexual abstinence rather than condom use during RTI treatment. It would appear that from these physicians' perspective it is easier for women to negotiate sexual abstinence than condom use with their partners. But sexual abstinence is ineffective if followed only by women; if their partners engage in extramarital sex, it could lead to reinfection (Merrill et al., 1990; Roter et al., 1990; Population Reports, 1993). The physicians interviewed also reported that information was provided only to women because men did not come to the clinic. This places the burden of responsibility on the woman for both her own treatment and that of her partner, in addition to the negotiation of sexual abstinence or condom use (Elias, 1991).

Our findings were limited to one region and cannot, without further studies, be generalized to the entire country. However, they appear to support what has been called the "culture of silence" (Dixon-Mueller \& Wasserheit, 1991). $M$ any women do not discuss the sexual transmission of infections with their doctors because of their inhibitions, and they repeat the pattern that is socially transmitted. In addition, physicians frequently fail to bring up issues related to sexuality and RTIs, because they have difficulty addressing this topic during consultation (Antrobus et al., 1994). This "culture" fosters the persistence and spread of sexually transmitted diseases and RTIs, especially in developing countries (Wasserheit, 1989).

Some RTIs, especially when recurrent, can cause tubal infertility. The main difference between primary tubal infertility due to RTI and other types of infertility is that it can be prevented by providing women with adequate information about transmission and the risk which RTIs represent for their reproductive future. In order to have an impact and lead to behavioral changes, this information must be clear, specific, and significant within the context of women's lives, to encourage women to adopt preventive measures and avoid future RTIs. More studies in different regions of the country are necessary to assess women's perspectives and physicians' attitudes towards implementation of adequate counseling in relation to RTIs. 


\section{Acknowledgments}

This study received partial funding from the UNDP/ UNFPA/WHO/World Bank Special Program of Research, Development, and Research Training in Human Reproduction, World Health Organization, Geneva, Switzerland.

\section{References}

ANTROBUS, P.; GERM AIN, A. \& NOWROJEE, S., 1994. Challenging the Culture of Silence. Building Alliances to end Reproductive Tract Infections. New York: International Women's Health Coalition.

DENZING, N. \& LINCOLN, Y., 1994. Handbook of Qualitative Research. Thousand Oaks: Sage.

DIXON-MUELLER, R. \& WASSERHEIT, J., 1991. The Culture of Silence. Reproductive Tract Infections Among Women in the Third World. New York: International Women's Health Coalition.

ELIAS, C., 1991. Sexually Transmitted Diseases and the Reproductive Health of Women in Developing Countries. New York: The Population Council.

FERNANDES, M. S. \& BAHAM ONDES, L., 1996. Incidência dos fatores etiológicos de esterilidade conjugal nos hospitais universitários de Campinas. Revista Brasileira de Ginecologia e Obstetricia, 18:29-36.

HINTING, A.; BANDASO, R. \& ROWE, P., 1993. TheImpact of Infection on ReproductiveHealth. Surabaya: Mediproc Ltd.

MERRILL, J. M.; LAUX L. F. \& THORNBY, J. I., 1990. Why doctors have difficulty with sex histories. Southern Medical Journal, 83:613-617.

MINAYO, M. C. S., 1993. O Desafio do Conhecimento. Pesquisa Qualitativa em Saúde. São Paulo: Editora Hucitec/Rio de Janeiro: ABRASCO.
POPULATION REPORTS, 1993. Controlling Sexually Transmitted Diseases. Population Information Program. Baltimore: The John Hopkins University. PATTON, M. Q., 1991. Qualitative Evaluation and Research Methods. Newburry Park: Sage.

ROTER, D. L.; KNOWLES, N.; SOM M ERFIELD, M . \& BALDWIN, J., 1990. Routine communication in sexually transmitted disease clinics: An observational study. American Journal of Public Health, 80:605-606.

ROWE, P. J. \&VIKHLYAEVA, E. M., 1988. Diagnosis and Treatment of Infertility. Toronto: Hans Huber/ World Health Organization.

SOCIETY FOR ASSISTED REPRODUCTIVE TECHNOLOGY, 1998. Assisted reproductive technology in the United States and Canada: 1995 results generated from the American Society for Reproductive Medicine/ Society for Assisted Reproductive Technology Registry. Fertility and Sterility, 69:389-398.

UN (United Nations), 1994. Report of the International Conference of Population and Development. Document A.Conf 171/13. Cairo: UN.

WASSERHEIT, J. N., 1989. The significance and scope of reproductive tract infections among Third World women. International Journal of Gynecology and Obstetrics, 2:145-168. 